\title{
CNJ: O PANORAMA DE UMA DÉCADA NA GESTÃO DO JUDICIÁRIO BRASILEIRO
}

\author{
Marco Antonio Barbosa* \\ José Luiz Parra Pereira**
}

SUMÁRIO: Introdução; 2 O Impacto da EC $n^{\circ}$ 45/2004; 3 Criação do Órgão e o Controle Externo; 40 Papel do Órgão e a Participação da Sociedade Civil; 50 Controle Judicial do STF como Cúpula do Poder Judiciário; 6 Considerações Finais; Referências.

RESUMO: Aborda-se a atuação e o desempenho do Conselho Nacional de Justiça na última década, apresentando panorama que se inicia antes da sua criação, passando por discussões legislativas, aprovação da $\mathrm{EC} \mathrm{n}^{0}$ 45/2004, análise de suas atribuições, o tema da participação da sociedade civil, a influência do STF em suas decisões e perspectivas na gestão do Poder Judiciário. Conclui-se pela necessidade de aproximação do CNJ da sociedade civil por meio da participação democrática na gestão do Poder Judiciário.

PALAVRAS-CHAVE: Conselho Nacional de Justiça; Gestão; Participação; Reforma do judiciário.

\section{THE BRAZILIAN COUNCIL OF JUSTICE: A SURVEY OF A TEN-YEAR-OLD MANAGEMENT OF THE BRAZILIAN COURTS}

\begin{abstract}
The activities and performance of the Brazilian Council of Justice during the last ten years are analyzed. Survey starts prior to its establishment. It describes legislative discussions and the approval of CE 45/2004, analysis of its attributions, participation of civil society, the influence of HFC and its decisions, and the perspectives within the administration of the Courts. Results reveal that the Brazilian Council of Justice should be close to civil society through a democratic participation within the Courts' administration.
\end{abstract}

KEY WORDS: Brazilian Council of Justice; Reform of the Courts; management; Participation.

\footnotetext{
Doutor em Direito pela Universidade de São Paulo (USP); Docente, pesquisador e orientador do Curso de Graduação em Direito e do Programa de Mestrado em Direito da Sociedade da Informação do Centro Universitário das Faculdades Metropolitanas Unidas (FMU), São Paulo (SP), Brasil; E-mail: marco.barbosa@fmu.br

** Mestrando no Programa de Mestrado em Direito da Sociedade da Informação no Centro Universitário das Faculdades Metropolitanas Unidas (FMU), São Paulo (SP), Brasil
} 


\section{CNJ: EL PANORAMA DE UNA DÉCADA EN LA GESTIÓN DEL JUDICIARIO BRASILEÑO}

RESUMEN: Se aborda la actuación y el desempeño del Consejo Nacional de Justicia en la última década, presentando el panorama que se inicia antes de su creación, pasando por discusiones legislativas, aprobación de la EC 45/2004, análisis de sus atribuciones, el tema de la participación de la sociedad civil, la influencia del STF en sus decisiones y perspectivas en la gestión del Poder Judiciario. Se concluye por la necesidad de acercamiento del CNJ de la sociedad civil por medio de la participación democrática en la gestión del Poder Judiciario.

PALABRAS-CLAVE: Consejo Nacional de Justicia; Gestión; Participación; Reforma del judiciario.

\section{INTRODUÇÃO}

O objetivo deste trabalho é discutir o papel do Conselho Nacional de Justiça - CNJ como órgão de controle da atuação administrativa e financeira do Judiciário. Além disso, também pretende-se analisar a instituição e refletir sobre os motivos de sua criação, sobre suas atribuições e sobre os rumos do Poder Judiciário, tendo em vista a prestação jurisdicional de maior qualidade, na perspectiva de serviços mais céleres e mais satisfatórios do ponto de vista dos jurisdicionados sob a liderança e controle do CNJ.

A proposta do estudo não é de pura submissão à vontade do legislador e de sua real intenção ao criar o CNJ, mas discutir o que efetivamente foi realizado pelo órgão no ano em que se celebra uma década da sua criação, propondo um balanço de suas atividades, onde analisam-se as resistências enfrentadas, os êxitos de sua atividade, os limites de sua participação, as fragilidades de sua estrutura e as tendências de sua atuação.

Reconhecendo que o CNJ contribuiu positivamente na gestão do Judiciário ao longo desta década e proporcionou maior transparência social, apresentam-se críticas à magistratura, que através de suas entidades de classe acentua a indignação da opinião pública ao promover a valorização de privilégios dissociados do respeito ao erário público, sem externar efetiva preocupação com a melhoria do sistema judiciário brasileiro, com ressalva àqueles que ainda atuam em busca de um sistema 
mais justo e democrático, os quais constituem minoria na realidade de "república colonizada".

Além disso, busca-se resgatar a discussão sobre a democratização do Poder Judiciário e participação da sociedade civil, proposta por Andrei Koerner e Roberto Fragalhe Filho, na medida em que a criação do CNJ implicou em certo esvaziamento da questão, a qual ressurge e demonstra sua relevância com o crescimento do movimento em prol de maior autonomia aos magistrados na elaboração da nova Lei Orgânica da Magistratura Nacional (LOMAN). Esse movimento deixa de fora a importante e necessária discussão acerca da ampliação da participação democrática na elaboração do texto da referida lei. Caso, por hipótese, continue na mesma direção de desprezar a participação dos jurisdicionados resultará na ainda maior concentração de poder à classe dos magistrados.

Por fim, mas não menos importante, aborda-se a influência direta do STF nas decisões e resoluções do Conselho, o qual, como se percebe, vai muito além de um órgão com função meramente revisora da atividade administrativa do Conselho, interferindo sem qualquer melindre nas decisões de acordo com seus interesses, inclusive com fins políticos.

Em outras palavras, procura-se, sem a pretensão de exaurir o tema, analisar os bastidores da reforma arquitetada pela EC $n^{0} 45 / 2004$ e os interesses envolvidos em sua tramitação, buscando refletir ainda se houve mudança através da "nova configuração" proposta na alteração legislativa ou apenas o aceite de antigos resquícios do período autoritário, balanço que é possível após uma década de existência do gestor do Judiciário brasileiro.

O método empregado é o dedutivo, com técnica de pesquisa bibliográfica e documental, com base no referencial teórico relativo à democratização do Poder Judiciário e participação da sociedade civil, conforme, especialmente, a proposta de Andrei Koerner e Roberto Fragalhe Filho.

\section{O IMPACTO DA EC N45/2004: A NECESSÁRIA REFORMA DO JUDICIÁRIO}

Em linhas gerais, a proposta de emenda constitucional relativa à reforma do Poder Judiciário, originalmente apresentada pelo então Deputado Hélio Bicudo (PTSP) em março de 1992, tramitou por mais de uma década no Congresso Nacional, 
enfrentando nesse período muitas resistências no meio político e no próprio Poder Judiciário, o qual apresentava-se fragmentado quanto ao assunto, especialmente quando o tema era a criação de um órgão de controle externo.

De uma leitura, ainda que breve, da exposição de motivos da proposta apresentada à época, são identificadas fortes críticas ao Judiciário por parte dos deputados, apontando o documento que o problema da morosidade e da gestão foi identificado de maneira clara já nos idos de 1975, quando o então presidente Ernesto Geisel concordou com a necessidade de ampla reforma e solicitou relatório detalhado ao Supremo Tribunal Federal para análise, o qual apontou as deficiências de um Poder retrógrado e corporativista ${ }^{1}$.

Descreve Joaquim Falcão que, no final da década de 80, início da década de 90, muitos intelectuais e cientistas das áreas sociais intensificaram a publicação de artigos de opinião e análises sobre o Poder Judiciário, evidenciando baixo grau de confiança por parte dos brasileiros e a necessidade de um Judiciário mais eficiente, o que em decorrência da nova Constituição de 1988 proporcionou mais força à ideia de reforma ${ }^{2}$.

Ainda analisando o cenário brasileiro da década 80/90, cumpre relembrar que o Estado passava por processo de abertura econômica, fortemente marcada por política liberal após muitos anos de regime ditatorial, com a promulgação de nova Constituição repleta de novos direitos individuais e coletivos. No mais, não se pode ainda deixar de pontuar que o país caminhava de uma sociedade fundamentalmente agrária em sua economia para uma sociedade massificada pelo consumo, com incentivos fiscais para produção de bens e serviços em busca de maior competitividade no cenário internacional, ocasionando significativo aumento dos litígios que posteriormente seriam transferidos ao Estado para pacificação ${ }^{3}$.

Nesse contexto, observa-se que muitos tribunais foram surpreendidos com essa nova realidade, não estando preparados para enfrentar um momento de massificação dos conflitos, permanecendo o legado de velhas práticas como os longos e formais votos, a rotina arcaica e burocrática de alguns cartórios, a resistência de magistrados e servidores no aprendizado de novas tecnologias, entre outras práticas

\footnotetext{
BRASIL, Diário do Congresso Nacional. Brasília, 1 maio 1992. Disponível em: < http://imagem.camara.gov.br/ Imagem/d/pdf/DCD01MAI1992.pdf\# page=7>. Acesso em: 24 set. 2015.

${ }^{2}$ FALCÃO, Joaquim. A história da reforma do poder judiciário e de sua estratégia pré-legislativa. In: STOCO, Rui; PENALVA, Janaína (Org.). Dez anos de reforma do judiciário e o nascimento do Conselho Nacional de Justiça. São Paulo: RT, 2015, p. 190.

3 BARBOSA, Marco Antonio; OLIVEIRA, Bruno Batista Costa. CNJ: Primavera brasileira ou defensor do estamento burocrático? Revista Crítica do Direito, v. 60, p. 1-24, 2014, p. 3.
} 
oriundas de um Judiciário que é fruto da colonização portuguesa que viveu seus primeiros séculos sob a égide de ordenações já ultrapassadas para a época.

Discorre Vladimir Passos de Freitas afirmando que o movimento pela criação de um controle externo ganhou mais adeptos em 1999 quando, a pedido do então Senador Antônio Carlos Magalhães (PFL-BA), foi instalada uma Comissão Parlamentar de Inquérito (CPI) para apuração da corrupção no Judiciário, momento histórico que protagonizou inúmeras acusações entre membros do Congresso e do Judiciário ${ }^{4}$.

Essa ideia de um controle externo ao Poder Judiciário não é genuinamente nacional, sendo possível citar uma série de países que utilizaram o sistema com experiências relevantes que certamente influenciaram o legislador brasileiro como o Conselho Disciplinar da Magistratura criado em Portugal no ano de 1892, o Conselho Superior da Magistratura criado na Itália em 1907, o Conselho da Justiça Federal criado no México em 1994, o Conselho da Magistratura criado no Peru em 1994, entre outros países, cujos Conselhos, guardadas as devidas proporções, exercem em comum a função disciplinar e a gestão e administração dos tribunais 5 .

No que diz respeito à proposta que tratava da reforma, é oportuno destacar que aquela inicialmente apresentada sofreu inúmeras alterações, cabendo ao então deputado Nelson Jobim (PMDB-RS) a ampliação da discussão sobre a crise do Judiciário, o que intensificou ainda mais os debates em torno da criação de um órgão de controle externo ${ }^{6}$. Relata Maria Tereza Sadek que, em 1999, a Associação de Magistrados Brasileiros (AMB) já demonstrava sinais de insatisfação com a temática de um órgão de controle externo dentro da reforma do Judiciário, demonstrando a associação ser contrária a ingerências externas, pois tal medida poderia acarretar um "controle político" do órgão que, segundo a AMB, deve ser independente ${ }^{7}$. Em continuidade à sua postura, em maio de 2000 , a associação novamente manifestouse, divulgando dessa vez um documento no qual apontava inúmeras críticas ao futuro $\mathrm{CNJ}$, declarando não admitir que o conselho fosse integrado por outras categorias profissionais que não exclusivamente magistrados ${ }^{8}$.

\footnotetext{
${ }^{4}$ FREITAS, Vladimir Passos de. A criação e o papel do conselho nacional de justiça. In: STOCO, Rui; PENALVA, Janaína (Org.). Dez anos de reforma do judiciário e o nascimento do Conselho Nacional de Justiça. São Paulo: RT, 2015, p. 510.

5 FREITAS. In: STOCO; PENALVA, op. cit., 2015, p. 508.

${ }^{6}$ SADEK, Maria Tereza (Org.). Reforma do judiciário. São Paulo: Fundação Konrad Adenauer, 2001, p. 10.

7 Ibidem, 2001, p. 116.

8 Ibidem, 2001, p. 117.
} 
Em contrapartida, outras associações como a Associação dos Juízes Federais e a Associação Nacional de Juízes para a Democracia, manifestaram-se favoráveis à criação de um órgão de controle externo, o que seguiu-se também entre os juízes mais jovens, que vislumbravam sobretudo a democratização da gestão judicial, e entidades representativas da sociedade civil, como a Confederação Geral dos Trabalhadores, Central Única dos Trabalhadores, Social Democracia Sindical e Confederação Nacional da Indústria9 ${ }^{9}$.

Cumpre destacar que a redação final da Proposta a Emenda Constitucional $\mathrm{n}^{\circ}$ 92/1992 continha previsão de punição até mais rigorosa aos magistrados, como a perda de cargo e não apenas a aposentadoria compulsória como ocorre hoje, sanção essa que poderia ser aplicada pelo CNJ por meio do voto de três quintos de seus membros, o que não foi aprovado em razão da polêmica do assunto ${ }^{10}$.

Não obstante os embates políticos e de interesses das classes envolvidas, as críticas à morosidade, falta de gestão e o descrédito do poder judiciário pela sociedade brasileira, apenas intensificaram-se ${ }^{11}$, fazendo com que em junho de 2004 o Min. Nelson Jobim, ex-deputado na época da proposta, assumisse a liderança em seu discurso de posse como presidente do STF: "O tema (da reforma) chegou à rua. A cidadania quer resultados. Quer um sistema judiciário que responda a três exigências: acessibilidade a todos, previsibilidade das decisões, e decisões em tempo social e economicamente tolerável"12.

Assim, apesar dos entraves e conflitos em torno da proposta, Joaquim Falcão afirma que o Min. Nelson Jobim tomou a decisão de liderar no STF o projeto em resposta ao significativo crescimento da insatisfação pública, além da percepção nítida de que o Judiciário estava internamente fragmentado ${ }^{13}$.

A resistência de muitos, em especial desembargadores mais antigos, perdurou, mas as vozes não foram suficientes para impedir a aprovação da Emenda Constitucional no 45/2004 alcunhada como "Reforma do Judiciário", a qual é vista

$\overline{9}$ SADEK, op. cit., 2001 , p. 117 , p. 119 e p. 154.

${ }^{10}$ TOMIO, Fabrício Ricardo de Limas; ROBL FILHO, Ilton Norberto. Accountability e independência judiciais: uma análise da competência do Conselho Nacional de Justiça (CNJ). Revista de Sociologia e Política, v. 45, p. $29-46,2013$, p. 40.

${ }^{11}$ OTTONI NETTO, Homero Benedicto. Judiciário continua na idade média na era da informação. São Paulo, 22 jul. 2003. Disponível em: < http://www.conjur.com.br/2003-jul-22/judiciario_continua_idade_media_informacao >. Acesso em: 24 set. 2015.

${ }^{12}$ BRASIL. Associação de Magistrados Brasileiros. Discurso proferido pelo Ministro Nelson Jobim na cerimônia de posse na presidência do STF. Brasília, 03 jun. 2004. Disponível em: < http://www.amb.com.br/portal/docs/ discursos/discurso.pdf $>$. Acesso em: 24 set. 2015.

${ }^{13}$ FALCÃO. In: STOCO; PENALVA, op. cit., 2015, p. 185. 
até hoje pela opinião pública como um marco divisor na história do Judiciário ${ }^{14}$, pois em que pese a alteração legislativa constitua um dos principais desafios políticos do país até a atualidade, representou um passo importante do Estado em reconhecer suas fragilidades e conceder status constitucional à matéria.

É oportuno destacar que, embora o objeto principal deste estudo seja o CNJ e o seu papel na gestão do Judiciário, a EC $\mathrm{n}^{\mathrm{O}}$ 45/2004 teve relevante importância no fortalecimento da Defensoria Pública, cujas funções eram exercidas basicamente por advogados em razão de convênio conhecido como Procuradoria de Assistência Judiciária (PAJ); na extinção dos cargos de juízes classistas; na implantação do processo eletrônico através do $\mathrm{CNJ}$; maior segurança jurídica nas decisões proferidas com a criação da súmula vinculante; além da criação do próprio Conselho Nacional de Justiça $(\mathrm{CNJ})$, o qual será aqui analisado.

Como se verá no decorrer do presente estudo, não se sustenta que a emenda constitucional 45 tenha sido a "salvadora" de todos os males do Judiciário e que hoje se tem um sistema efetivo de outorga da tutela jurisdicional, mas também não seria honesto menosprezar o advento de mudanças ocorridas no sistema judiciário com a sua promulgação, cujos reflexos podem ser experimentos por muitos brasileiros.

\section{A CRIAÇÃO DO ÓRGÃO E A ATIVIDADE DE CONTROLE EXTERNO}

O Conselho Nacional de Justiça (CNJ) foi instituído pela EC $\mathrm{n}^{0} 45 / 2004$, mediante a inclusão do artigo 103-B à Constituição Federal, o qual foi estabelecido como órgão de cúpula administrativa do Poder Judiciário, porém sem funções jurisdicionais. A composição do $\mathrm{CNJ}$ é definida no texto Constitucional, que é integrado por quinze membros, com idade superior a trinta e cinco anos e inferior a sessenta e seis, sendo nove membros oriundos do Poder Judiciário, dois do Ministério Público, dois da classe dos advogados e dois cidadãos com notável saber jurídico e reputação ilibada, os quais são indicados pelo legislativo.

Nesse momento, é importante relembrar que, historicamente, a autonomia dos tribunais estabelecida na Constituição era até então considerada uma vitória a todos os integrantes do Judiciário, pois após longo período de regime autoritário

\footnotetext{
${ }^{14}$ CAETANO, Flávio Crocce. Dez anos da reforma do judiciário. São Paulo, 16 dez. 2014. Disponível em: < http:// politica.estadao.com.br/blogs/fausto-macedo/dez-anos-da-reforma-do-judiciario/>. Acesso em: 25 set. 2015. Reforma do judiciário (EC45/04) - 10 anos depois. In: Migalhas. Brasil. Datado de 17 dez. 2014. Disponível em: $<$ http://www.migalhas.com.br/Quentes/17,MI212874,61044-Reforma + do + Judiciario +EC + 4504+10+anos + depois > . Acesso em: 25 set. 2015.
} 
o Poder possuía finalmente independência plena, estando livre de interferências externas que poderiam ameaçar sua autonomia, o que passou a ocorrer na visão de muitos (especialmente dos integrantes do próprio Poder Judiciário) com a inclusão de membros não integrantes da magistratura na composição do CNJ.

Por outro lado, a partir de análise desapaixonada e desinteressada de sua composição, verifica-se sem qualquer esforço que o órgão é formado predominantemente por integrantes da magistratura, ponto esse que foi e ainda é alvo de muitas críticas por parte da opinião pública e de especialistas independentes, tendo em vista que tal forma de composição favorece e possibilita o corporativismo nas discussões atinentes à magistratura e aos magistrados.

Vale frisar que ao criar o órgão, a mesma emenda constitucional atribuiulhe a função de realizar a organização e o planejamento de políticas institucionais (plano de metas, avaliação institucional, programas como o "Conciliar é legal" etc.), a fiscalização dos atos administrativos e o acompanhamento do cumprimento de regras disciplinares, o que mesmo após dez anos de sua criação ainda é motivo de discórdia dentro do próprio Poder Judiciário.

No que diz respeito à função disciplinar, grande celeuma existe, pois não obstante as sequenciais perdas da Associação de Magistrados Brasileiros (AMB) nas Ações Diretas de Inconstitucionalidade - ADIns n ${ }^{0}$ 3.367-DF e 4.638-DF, onde restou consignado no pleno do Supremo Tribunal Federal (STF) a natureza de órgão administrativo interno do Poder Judiciário ao CNJ, a inexistência de ofensa à independência de poderes, o caráter nacional do Judiciário e a competência concorrente do CNJ para decidir sobre a perda de cargo de magistrado vitalício, acompanham-se notícias recentes que demonstram movimentação da mesma associação para incluir o artigo 92, inciso IV, na nova Lei Orgânica da Magistratura Nacional (LOMAN), o qual dispõe como prerrogativa de juízes e desembargadores serem ouvidos exclusivamente por um par seu, na nítida tentativa de privilegiar o corporativismo ${ }^{15}$.

Após inúmeras críticas e manifestações públicas, inclusive de membros do CNJ, o Ministro Ricardo Lewandowski, atual presidente do CNJ, encaminhou ofício à Ordem dos Advogados do Brasil esclarecendo que o artigo 92, inciso IV seria revisado no projeto, pois não haveria a intenção de suprimir as atribuições do $\mathrm{CNJ}$ quanto a sua função disciplinar ${ }^{16}$, o que chama a atenção de toda a opinião

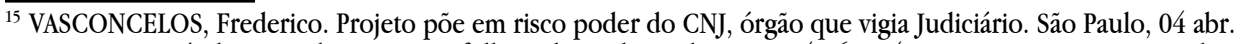
2015. Disponível em: <http://www1.folha.uol.com.br/poder/2015/04/1612249-projeto-poe-em-risco-poderdo-cnj-orgao-que-vigia-judiciario.shtml> . Acesso em: 25 set. 2015.

${ }^{16}$ ROLIM, Luciano. Captura corporativista do CNJ. São Paulo, 23 abr. 2015. Disponível em: < http://opiniao. estadao.com.br/noticias/geral,captura-corporativista-do-cnj-imp-,1674415> . Acesso em: 10 out. 2015.
} 
pública, pois no início do ano de 2015 o próprio Ministro afirmou que era tempo de rediscutir o patamar profissional e institucional dos juízes brasileiros que prestam um serviço inestimável ao país, o que se pensava tratar-se de um progresso e não um retrocesso para o país.

Infelizmente, a tentativa de minar as atribuições do $\mathrm{CNJ}$ não para por aí, pois a nova Lei Orgânica da Magistratura Nacional (LOMAN) ainda prevê em seu artigo $273, \S 5^{\circ}$ que "as metas e demais determinações aos tribunais" só poderão ser estabelecidas "após a oitiva dos seus respectivos presidentes", entre outras disposições que deixam clara a tentativa de neutralizar as atribuições do CNJ, em desrespeito àquilo que já foi matéria de análise pelo pleno do STF ${ }^{17}$.

Não por menos a nova lei ganhou inúmeras manchetes na grande mídia, tendo em vista que a minuta do projeto da nova Lei Orgânica da Magistratura Nacional (LOMAN) está sendo elaborada pelo próprio STF, com relatoria do Ministro Ricardo Lewandowski, antes do envio ao Congresso Nacional ${ }^{18}$, havendo notícias de que as associações de classe têm participado ativamente dessa discussão, o que por óbvio influenciará diretamente na versão final do documento, na medida em que tramita sem qualquer participação da sociedade civil ou de seus representantes ${ }^{19}$. Imperioso aqui citar as palavras da Corregedora Gisela Gondin Ramos, sobre essas novas investidas da Associação de Magistrados Brasileiros (AMB) em parceria com alguns Ministros do STF:

[...] o que se pretende fazer com o Conselho, hoje, é algo sem precedentes. Estão em pleno curso, sem vela ou coroa de flores, os preparativos para o cortejo fúnebre do $\mathrm{CNJ}$.

Se for aprovada como está a proposta da nova Lei Orgânica da Magistratura Nacional (Loman), o CNJ se transformará em uma repartição burocrática de pouco utilidade para o País. A pretexto de zelar pela autonomia administrativa dos tribunais - que, como bem mostra a história nacional, poucas vezes serviu ao bom funcionamento da Justiça - a proposta acaba com o Conselho Nacional de Justiça ${ }^{20}$.

A proposta da nova lei ainda multiplica os salários da categoria através

\footnotetext{
${ }^{17}$ TEIXEIRA, Paulo Eduardo Pinheiro. Mudanças previstas na nova Loman enfraquecem papel no CNJ. São Paulo, 11 abr. 2015. Disponível em: < http://www.conjur.com.br/2015-abr-11/paulo-teixeira-mudancas-previstas-loman-enfraquecem-cnj>. Acesso em: 25 set. 2015.

${ }^{18}$ ROCHA, Graciliano. Projeto do STF pode tornar Judiciário maior e mais caro. São Paulo, 24 maio. 2015. Disponivel em: <http://www1.folha.uol.com.br/poder/2015/05/1632909-projeto-do-stf-pode-tornar-judiciario-maior-e-mais-caro.shtml> . Acesso em: 12 out. 2015.

${ }^{19}$ KADANUS, Kelli. Proposta de nova LOMAN aumenta benefícios dos magistrados. Curitiba, 05 jun. 2015. Disponível em: < http://www.gazetadopovo.com.br/vida-publica/justica-e-direito/proposta-de-nova-loman-aumenta -beneficios-dos-magistrados-7davvag4n9gqi4688re0vboey>. Acesso em: 12 out. 2015.

${ }^{20}$ RAMOS, Gisela Gondin. O enterro precoce do CNJ. São Paulo, 09 abr. 2015. Disponível em: < http://politica. estadao.com.br/blogs/fausto-macedo/o-enterro-precoce-do-cnj/> . Acesso em: 25 set. 2015.
} 
de gratificações, bônus e indenizações, pois assim é possível driblar o limite de vencimentos estabelecidos na Constituição, não dependendo a magistratura brasileira dos reajustes de salário do STF, bem como não altera o período de férias a serem gozadas, permanecendo de 60 dias para todos os juízes do país, com o recebimento de dois abonos de um terço do salário nas respectivas férias.

Como bem aponta Joaquim Falcão em entrevista a Frederico Vasconcelos, a nova lei é em parte uma tentativa de reanálise de algo que já foi decidido pelo STF e de outra uma atitude que somente reforça o corporativismo do Judiciário, colocando toda a sociedade contra os interesses da categoria, na medida em que o CNJ não é um órgão dos juízes, tendo sido criado com o objetivo de ser "multirepresentativo", no intuito de tornar o Judiciário um poder aberto e participativo, com promotores, magistrados, procuradores, advocacia e sociedade ${ }^{21}$.

Diante de tal movimentação, o que se nota é a insistente tentativa de uma classe, representada por suas associações, em implementar a concentração de poder em seus pares, objetivando verdadeiro monopólio do controle disciplinar, sem demonstrar maior preocupação com o tema de efetividade da tutela jurisdicional ou modernização do Judiciário, tendo como único e primordial foco os vencimentos, benefícios e prerrogativas da categoria sob pretexto de uma "valorização dos subsídios" para preservação da carreira ${ }^{22}$.

Em análise sobre o tema do poder disciplinar cabe aqui registrar a visão de Ricardo Cunha Chimenti, magistrado da Justiça Estadual de São Paulo há 26 anos:

Essa premissa constitucional de que o CNJ pode e deve atuar de ofício, quando do exercício do poder disciplinar, tem em mira extirpar com uma doença crônica que era a soberania exclusiva da magistratura no julgamento de seus pares. Assim, quando se defende a ideia de que o CNJ pode e deve atuar de ofício, sem prejuízo da atuação do órgão censor local, enaltece que a competência entre o CNJ e os tribunais é, antes e acima de tudo, concorrente ${ }^{23}$.

Recorde-se, por oportuno, que um dos pilares da criação do CNJ era aproximar o cidadão brasileiro do sistema judiciário, sendo possível através de

${ }^{21}$ VASCONCELOS, Frederico. CNJ é da sociedade e não dos juízes. São Paulo, 07 abr. 2015. Disponível em: $<$ http://blogdofred.blogfolha.uol.com.br/2015/04/04/cnj-e-da-sociedade-nao-dos-juizes/>. Acesso em: 11 out. 2015.

${ }^{22}$ GOMIDE, Raphael. Projeto de lei prevê até 17 salários e aumenta benefícios a juízes. Rio de Janeiro, 03 jul. 2015. Disponível em: < http://epoca.globo.com/tempo/noticia/2015/07/projeto-de-lei-preve-ate-17-salarios-e -aumenta-beneficios-juizes.html>. Acesso em: 03 out. 2015.

${ }^{23}$ CHIMENTI, Ricardo Cunha. A corregedoria nacional de justiça-avanços e resistências. In: STOCO, Rui; PENALVA, Janaína (Org.). Dez anos de reforma do judiciário e o nascimento do Conselho Nacional de Justiça. São Paulo: RT, 2015, p. 366. 
informações públicas de interesse coletivo exercer maior transparência na gestão ${ }^{24}$. Por outro lado, defende-se aqui que essa competência concorrente do CNJ em seu jaez correcional apenas contribui com a ação disciplinar, pois reflete de início a provável ineficiência do controle até então realizado pelos tribunais, além de permitir maior equilíbrio na apuração e aplicação da sanção, evitando assim possível corporativismo nas decisões que tratam de atos infracionais ou até mesmo de corrupção.

\section{O PAPEL DO ÓRGÃO E A PARTICIPAÇÃO DA SOCIEDADE CIVIL}

Não obstante as críticas em contrário, sustenta-se que o advento do $\mathrm{CNJ}$ representou novo momento para o Poder Judiciário e para a sociedade brasileira, pois permitiu maior transparência ao prestar contas por meio de seus relatórios, significativo aprimoramento na tarefa de planejar, estabelecer políticas públicas e modernizar a estrutura do Judiciário, valendo lembrar que antes da organização do CNJ o acesso a informações relevantes de funcionamento do Poder Judiciário era precário, sendo difícil conseguir saber quantas ações foram distribuídas e encerradas em determinado Foro, quantos servidores estavam lotados em determinada Comarca, qual a taxa de congestionamento, quais os gastos de consumo (água, energia, papel etc.), qual o tempo médio de determinadas ações em uma Comarca, entre outras informações que contribuem para o acompanhamento e fiscalização dos atos que envolvem as atividades judiciais.

Analisando os avanços que o CNJ proporcionou na gestão do Judiciário brasileiro, Maria Tereza Sadek destaca que antes da criação do órgão alguns Tribunais não conseguiam afirmar sequer qual era o número total de juízes existentes em sua área de atuação, apresentando informações estatísticas sem o mínimo de confiabilidade ${ }^{25}$. Nas palavras de Antônio de Pádua Ribeiro, o CNJ consubstanciouse "como órgão de governança do Poder Judiciário e de sua interlocução com a sociedade", afirmando ainda que o órgão possibilitou o fim do nepotismo, limitou os vencimentos de integrantes do Judiciário, trouxe seriedade aos concursos públicos,

\footnotetext{
${ }^{24}$ SILVA, Rosane Leal da; HOCH, Patrícia Adriani; RIGHI, Lucas Martins. Transparência pública e a atuação normativa do CNJ. Revista Direito GV, v. 18, p. 489-514, 2013, p. 502.

${ }^{25}$ SADEK, Maria Tereza. CNJ: impactos no judiciário e na sociedade. In: STOCO, Rui; PENALVA, Janaína (Org.). Dez anos de reforma do judiciário e o nascimento do Conselho Nacional de Justiça. São Paulo: RT, 2015, p. 305.
} 
implantou o processo eletrônico, estimulou a prática de conciliação, entre outras atividades $^{26}$. Ainda, ao comentar os impactos do CNJ como instituição, acentua Maria Tereza Sadek: "A partir da existência do CNJ o Judiciário deixou de ser um conjunto de ilhas isoladas, agindo sem coordenação e unidade; tornou-se menos hermético; mais aberto à sociedade e menos auto referido" ${ }^{27}$.

$\mathrm{Na}$ visão de alguns estudiosos ${ }^{28}$, a criação do $\mathrm{CNJ}$ possibilitou não só a gestão efetiva do Judiciário como também uma abertura para a participação de atores públicos e privados, proporcionando maior discussão e envolvimento da sociedade civil em vários setores e assuntos, os quais podem contribuir e enriquecer o debate por muitas vezes estarem mais próximos da situação.

A própria página institucional do órgão ${ }^{29}$ revela uma abertura de diálogo com a sociedade civil, citando na maioria de seus programas e ações a possibilidade de participação social, no intuito de demonstrar um rompimento de prática do Judiciário com a sua criação e maior transparência na sua atuação.

Passados dez anos de sua criação, o CNJ consolidou êxitos como aposentadoria compulsória de magistrados ${ }^{30}$ no âmbito disciplinar; a criação do programa "pai presente"31 que estimula e facilita o reconhecimento de paternidade; o relatório "justiça em números", onde divulga anualmente informações dos noventa tribunais brasileiros, permitindo maior gestão; forte atuação contra o nepotismo no Judiciário ${ }^{32}$; implementação do processo eletrônico ${ }^{33}$; implementação de metas

\footnotetext{
${ }^{26}$ RIBEIRO, Antônio de Pádua. A importância do CNJ na implantação de uma nova ordem judiciária no Brasil. In: STOCO, Rui; PENALVA, Janaína (Org.). Dez anos de reforma do judiciário e o nascimento do Conselho Nacional de Justiça. São Paulo: RT, 2015, p. 73.

${ }^{27}$ SADEK. In: STOCO; PENALVA, op. cit., 2015, p. 305.

${ }^{28}$ BOCHENEK, Antonio Cesar; DALAZOANA, Vinícius; RISSETTI, Vinícius Rafael. Good governance e o Conselho Nacional de Justiça. Revista Direito GV, v. 18, p. 535-554, 2013, p. 537.

${ }^{29}<$ http://www.cnj.jus.br/>. Acesso em: 12 out. 2015.

${ }^{30}$ VASCONCELLOS, Marcos de. Conselho Nacional de Justiça aposentou 12 juízes em 2013. São Paulo, 07 jan. 2014. Disponível em: < http://www.conjur.com.br/2014-jan-07/doze-magistrados-foram-aposentados-compulsoriamente-cnj-2013 > . Acesso em: 12 out. 2015; VASCONCELLOS, Marcos de. CNJ puniu cinco magistrados e afastou outros cinco em 2014. São Paulo, 02 fev. 2015. Disponível em: < http://www.conjur.com.br/2015fev-02/cnj-puniu-cinco-magistrados-afastou-outros-cinco-2014>. Acesso em: 12 out. 2015.

${ }^{31}$ FARIELLO, Luiza de Carvalho. Programa pai presente completa cinco anos e se consolida no país. Brasília, 07 ago. 2015. Disponível em: < http://www.cnj.jus.br/noticias/cnj/80089-programa-pai-presente-completa-cinco -anos-e-se-consolida-no-pais > . Acesso em: 12 out. 2015.

${ }^{32}$ PINHEIRO, Aline. Leia a resolução contra o nepotismo aprovada pelo CNJ. São Paulo, 18 out. 2005. Disponível em: < http://www.conjur.com.br/2005-out-18/leia_resolucao_nepotismo_aprovada_cnj>. Acesso em: 12 out. 2015.

${ }^{33}$ MACEDO, Fausto; COUTINHO, Mateus. CNJ aprova processo judicial eletrônico em meio às críticas de advogados e servidores. São Paulo, 17 dez. 2013. Disponível em: < http://politica.estadao.com.br/blogs/fausto-macedo/cnj-aprova-processo-judicial-eletronico-em-meio-as-criticas-de-advogados-e-servidores/> . Acesso em: 12 out. 2015.
} 
de produtividade ${ }^{34}$, com expressiva quantidade de ações julgadas; realização de mutirões carcerários periódicos ${ }^{35}$, com objetivo de revisão das penas e inspeção dos estabelecimentos prisionais; a criação do Sistema Nacional de Bens Apreendidos $(\mathrm{SNBA})^{36}$, no intuito de consolidar as informações sobre os bens apreendidos em procedimentos criminais; entre outras medidas para o aperfeiçoamento do sistema judicial.

A despeito da notória melhoria dos serviços e inovação no desempenho da prestação jurisdicional, as quais demonstram a importância do gerenciamento, observa-se que esse "acesso" às informações demonstra maior transparência, mas não representa uma aproximação do Judiciário com a sociedade brasileira, a qual ainda permanece distante dos magistrados, com raras exceções. Em entrevista concedida ao jornal O Globo em outubro de $2011^{37}$, o jurista Hélio Bicudo, que originariamente apresentou a proposta da $\mathrm{EC} \mathrm{n}^{\circ} 45 / 2004$, registra que a ideia inicial de criação do CNJ era aproximar o Judiciário, como instituição representativa, da sociedade brasileira, submetendo assim as ações do Poder ao crivo da população, o que não foi possível diante da sua composição, sendo assim desfavorável a esse tipo de atuação, embora alguns estudiosos defendam que a participação da sociedade é cada vez maior nos casos de repercussão social ou econômica após a organização do CNJ, na medida em que sua estrutura permite participação política e democrática na tomada de decisão dos assuntos importantes para a administração da justiça ${ }^{38}$. No entanto, ousa-se aqui discordar de tal entendimento, pois mesmo com o papel relevante dos meios de comunicação (Internet, TV etc.) e a interação do próprio $\mathrm{CNJ}$ nas redes sociais, grande parte da população brasileira ainda vê o Judiciário como um poder fechado, distante e repleto de formalidades que mais "atrasam" a busca de seus "direitos" em virtude da burocracia. Nesse sentido, deve-se ponderar que algumas dessas "formalidades" podem ser condição necessária à segurança

\footnotetext{
${ }^{34}$ MONTENEGRO, Manuel Carlos. Meta de produtividade resultou em 87 milhões de ações julgadas desde 2010. Brasília, 23 jun. 2015. Disponível em: <http://www.cnj.jus.br/noticias/cnj/79701-meta-de-produtividade-resultou-em-87-milhoes-de-acoes-julgadas-desde-2010>. Acesso em: 12 out. 2015.

${ }^{35}$ MENDES, Gilmar. Mutirões carcerários, uma aula de Brasil. São Paulo, 16 abr. 2010. Disponível em: < http:// opiniao.estadao.com.br/noticias/geral,mutiroes-carcerarios-uma-aula-de-brasil,539075 >. Acesso em: 12 out. 2015.

${ }^{36}$ MACEDO, Fausto. CNJ manda vender bens apreendidos pela Justiça. São Paulo, 20 fev. 2010. Disponível em: $<$ http://www.estadao.com.br/noticias/geral,cnj-manda-vender-bens-apreendidos-pela-justica,513978> . Acesso em: 12 out. 2015.

${ }^{37}$ GOÉS, Bruno. Fiscalização do Poder Judiciário está entranhada na sociedade brasileira. Rio de Janeiro, 07 out. 2011. Disponível em: < http://oglobo.globo.com/politica/fiscalizacao-do-poder-judiciario-esta-entranhada-nasociedade-brasileira-diz-helio-bicudo-2743001>. Acesso em: 27 set. 2015.

${ }^{38}$ BOCHENEK; DALAZOANA; RISSETTI, op. cit., 2013, p. 543.
} 
jurídica da prestação da tutela jurisdicional, mas sugere-se uma reflexão quanto à participação da sociedade civil e até mesmo do cidadão, individualmente falando, na gestão direta do Judiciário nas inúmeras audiências e atos judiciais que são realizadas por nosso país.

De maneira clara e objetiva ao tratar sobre o estímulo do CNJ ao encerramento de processo por meio da conciliação, como exemplo, Marco Antonio Barbosa e Bruno Batista da Costa de Oliveira expõem que na ânsia de descongestionar o Judiciário, muitos magistrados designam seguidas audiências de conciliação das quais sequer participam, praticamente impondo, ainda que de maneira velada, uma solução "amigável" ao jurisdicionado, o que apenas aumenta o desprestígio de toda a categoria, pois o cidadão acaba por ter a sensação de desprezo do Judiciário para com aquele, problema que não raro perturba o sono e lhe retira a paz, tendo em vista que não existe comunicação entre as partes e as audiências chegam a durar muitas vezes, no máximo de 10 a 15 minutos $^{39}$.

Mas o problema não é apenas esse. Segundo muitos estudiosos, a própria composição do órgão revela a atenção do legislador quanto à importância da participação da sociedade, pois dedicou à estrutura do CNJ apenas dois membros que serão "cidadãos, de notável saber jurídico e reputação ilibada", na qualidade de representantes dos cidadãos nas decisões da casa. Considera-se essa representação pouco significativa e ademais disso e ainda mais grave é o fato de que esses cidadãos tenham que ser bacharéis em Direito o que transforma o Conselho em uma corporação de profissionais do Direito, exclusivamente.

Vale ponderar que, em uma década de existência do órgão, não se tem notícia de nenhuma convocação ou envolvimento da sociedade na escolha desses dois nomes, os quais são escolhidos "às escuras nos corredores da Câmara e Senado, à distância e revelia da sociedade" como bem acentua Antônio Escrivão Filho ${ }^{40}$. Digase de passagem, nenhuma audiência pública, debate ou consulta pública foi realizada até hoje para indicação e escolha dos conselheiros que teoricamente representam a sociedade civil, o que demonstra a total ausência de representação de fato da sociedade. Mais além, alguns estudiosos chegam a questionar se o órgão é conhecido pelos cidadãos brasileiros, bem como se a população recorreria ao conselho em caso de suspeita de desvio funcional por parte de um magistrado, advogando a ideia de

\footnotetext{
${ }^{39}$ BARBOSA; OLIVEIRA, op. cit., 2013, p. 19.

${ }^{40}$ ESCRIVÃO FILHO, Antônio. Transparência e participação social na indicação de conselheiros para o CNJ. Curitiba, 18 jan. 2012. Disponível em: < http://terradedireitos.org.br/2012/01/19/transparencia-e-participacaosocial-na-indicacao-de-conselheiros-para-o-cnj/> . Acesso em: 11 out. 2015.
} 
que o CNJ precisa aparecer à sociedade, divulgar o seu trabalho como instituição, pois muitos sequer o conhecem ${ }^{41}$.

Considerando essa composição do Conselho, não é de se espantar que o Poder Judiciário ainda seja considerado um dos poderes mais elitistas e formalistas do Estado contemporâneo, com maior descrédito junto à população brasileira, o qual ano a ano perde ainda mais a confiança da sociedade, não obstante a sua suposta aproximação após a criação do CNJ.

Ao propor reflexão sobre a composição do CNJ, Técio Lins e Silva defende que não há paridade entre os membros do órgão, na medida em que nove dos quinze integrantes do conselho são oriundos do Poder Judiciário, o que indica uma hierarquia, ainda que sutil, na distribuição das posições, sendo primordial visão convergente para tratamento das relações entre oficiais do mesmo ofício, onde juízes, promotores e advogados sejam responsáveis pela afirmação da democracia ${ }^{42}$. De outro lado, o Min. César Peluso, em seu voto da ADIn n ${ }^{0} 3.367 / \mathrm{DF}$, sustentou que a participação popular no CNJ ocorre através desses dois cidadãos que compõem a sua estrutura. Afirmou o ministro que "[...] a existência, no Conselho, de membros alheios ao corpo da magistratura, além de viabilizar a erradicação do corporativismo, estende uma ponte entre o Judiciário e a sociedade, permitindo a oxigenação da estrutura burocrática do Poder e a resposta a críticas severas”³. No entanto, entendese que esse foi o ponto central de toda a discussão quando da criação do CNJ, pois diante dos embates protagonizados pela classe de magistrados, o legislador optou por compor o Conselho com composição majoritária de membros do Poder Judiciário, pois assim a proposta seria mais bem vista pela categoria e aceita. Torna-se oportuno, nesse momento, repetir as palavras de Andrei Koerner e Roberto Fragale Filho acerca da participação da sociedade:

O tema da participação cidadã no Judiciário não é sinônimo de controle externo e nem é contrário à democratização. Ele é constituído das instituições representativas contemporâneas, nas quais, desde as revoluções burguesas rejeitava-se a magistratura togada como expressão do Antigo Regime e se demandava que os cidadãos fossem julgados pelos próprios pares ${ }^{44}$.

\footnotetext{
${ }^{41}$ FRANCO, Ivan Candido da Silva de; CUNHA, Luciana Gross. O CNJ e os discursos do direito e desenvolvimento. Revista Direito GV, v. 18, p. 515-534, 2013, p. 530.

${ }^{42}$ SILVA, Técio Lins e. O Conselho Nacional de Justiça na visão de um advogado que viveu os dois lados da tribuna. In: STOCO, Rui; PENALVA, Janaína (Org.). Dez anos de reforma do judiciário e o nascimento do Conselho Nacional de Justiça. São Paulo: RT, 2015, p. 502.

${ }^{43}$ STF - Pleno - Adin no 3.367/DF - Rel. Min. César Peluso, decisão: 13.4.2005. Informativo STF no 383.

${ }^{44}$ KOERNER, Andrei; FRAGALE FILHO, Roberto. Do controle externo à participação cidadã: por uma revisão do modelo do judiciário brasileiro. In: STOCO, Rui; PENALVA, Janaína (Org.). Dez anos de reforma do judiciário e o nascimento do Conselho Nacional de Justiça. São Paulo: RT, 2015, p. 63.
} 
Isso não significa dizer que se está aqui defendendo modelo da magistratura com juízes leigos. O que se pretende é tão somente provocar a reflexão sobre a participação do cidadão em órgão que não possui atividade jurisdicional e presta relevante função de gestão administrativa do Judiciário, sendo absolutamente razoável contar com a participação e o apoio de profissionais de outras áreas, o que proporcionaria maior diálogo entre o campo do direito e as demais ciências mas, sobretudo, entre o direito e a cidadania. A propósito, informa Paulo Luiz Schmidt que, no início de 2004, a Associação dos Magistrados da Justiça do Trabalho (ANAMATRA) apresentou proposta onde o CNJ seria composto por 21 membros, sendo 13 o número de integrantes do Poder Judiciário e 08 cargos à disposição da sociedade civil e à comunidade científica, oportunidade em que registrou ser contra a participação de instituições de interesse corporativo direto, como o caso da Ordem dos Advogados do Brasil (OAB), que hoje compõe a estrutura do órgão ${ }^{45}$. Mesmo passados dez anos da criação do CNJ, não se consegue ponderar ou afirmar com conviç̧ão que tal proposta seria a mais adequada para a efetiva participação da sociedade civil, contudo, observa-se que a atual estrutura está muito aquém daquilo que se imagina como ideal, sendo necessária até mesmo a realização de mais audiências públicas no intuito de ouvir críticas, sugestões e propostas da comunidade, as quais devem ser amplamente divulgadas.

Sustentam Andrei Koerner e Roberto Fragale Filho que, embora a ADIn $\mathrm{n}^{\mathrm{o}} 3.367$ proposta pela Associação dos Magistrados Brasileiros (AMB) tenha sido julgada improcedente, nos relatórios do acórdão proferido restou consignado o $\mathrm{CNJ}$ como órgão interno do Judiciário, afastando-se assim a possibilidade da participação cidadã na governança do Poder Judiciário, tornando-se este em local privilegiado de "negociações corporativas" ${ }^{4}$. Por outro lado, nessa mesma análise acerca da aproximação do Judiciário com a sociedade civil e efetiva participação do cidadão, propõem Marco Antonio Barbosa e Bruno Batista da Costa de Oliveira que uma maneira de aproximação seria a reforma da Lei Orgânica da Magistratura Nacional (LOMAN), a qual é de 1979 e apresenta estrutura retrógrada em absoluta dissonância com um Poder democrático ${ }^{47}$. Isso, porém, parece não surtir efeito neste momento, pois como se viu, existe forte movimentação das associações de magistrados para

${ }^{45}$ SCHMIDT, Paulo Luiz. Dez anos de CNJ: constante aprimoramento. In: STOCO, Rui; PENALVA, Janaína (Org.). Dez anos de reforma do judiciário e o nascimento do Conselho Nacional de Justiça. São Paulo: RT, 2015, p. 353.

${ }^{46}$ KOERNER; FRAGALE FILHO. In: STOCO; PENALVA, op. cit., 2015, p. 65.

${ }^{47}$ BARBOSA; OLIVEIRA, op. cit., 2013, p. 21. 
que a referida lei apenas retire algumas atribuições do Conselho, não agregando em nada quanto à aproximação do Judiciário ou a participação direta da sociedade civil, defendendo as associações de classe dos magistrados apenas os interesses econômicos e privilégios da categoria.

No intuito de contribuir com a discussão e seguindo a linha de raciocínio exposta por Andrei Koerner e Roberto Fragale Filho, propõe-se pensar em ir além da existência de dois cidadãos formados em Direito na composição do CNJ, ponderando pela participação de profissionais de outras áreas, o que indubitavelmente contribuiria ao debate, especialmente aqueles das áreas sociais, como antropologia, ciência política e ciências sociais ${ }^{48}$. Nesse ponto, cumpre relembrar que na época das discussões acerca do projeto quanto à participação de membros externos ao Poder Judiciário no conselho, uma das principais justificativas das entidades de classe era a falta de conhecimento específico sobre o funcionamento da justiça, a qual era e é nitidamente corporativista, acentuando as características de um poder fechado, obscuro e rígido ${ }^{49}$.

Não se pode negar que estabelecer índices de produtividade à magistratura e elaborar um plano de gestão unificado do Poder Judiciário é fundamental na prestação jurisdicional, mas o diálogo com a sociedade civil organizada e movimentos sociais se faz necessário para ampliação dos debates de interesse da coletividade e democratização da justiça. No que diz respeito à participação da sociedade civil, parece indiscutível que o tema é extremamente relevante, porquanto é ela a destinatária final da prestação jurisdicional, mas sabe-se que o assunto é um desafio, sendo necessário criarem-se mecanismos efetivos para que o $\mathrm{CNJ}$ não se torne mais uma unidade burocrática sem qualquer finalidade efetiva de contribuir para o aperfeiçoamento da prestação jurisdicional, dentre tantas existentes em nosso país.

\section{O CONTROLE JUDICIAL DO STF COMO CÚPULA DO PODER JUDICIÁRIO}

Outro ponto polêmico, mas não menos importante, é o mecanismo de revisão judicial das decisões e resoluções do CNJ pelo STF, disposto no art. 102, inciso I, alínea r da Constituição Federal, o que amplia, e muito, o grau de influência da Suprema Corte na construção institucional do órgão, possibilitando até mesmo a intervenção judicial no sistema político-administrativo do Poder Judiciário.

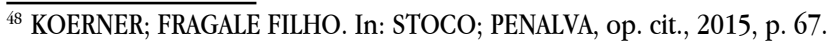

${ }^{49}$ FRANCO; CUNHA, op. cit., 2013, p. 526.
} 
Como visto anteriormente, um dos temas centrais de discussão antecedentes à criação do $\mathrm{CNJ}$ foi a independência do Poder Judiciário, fundamentando os magistrados que a criação de um órgão externo afetaria a livre convicção nos julgamentos, na medida em que os juízes temeriam punições no desempenho de suas funções. Logo o argumento sucumbiu, pois para a aprovação do projeto o legislativo incluiu o controle judicial pelo STF como cúpula do Poder Judiciário, passando a corte a ser responsável por essa missão de conceder a última palavra em discussões que envolvam o conselho ${ }^{50}$.

Apenas a título de exemplo, pode-se citar as ADIns $n^{0}$ 3.367-DF e 4.638-DF, onde o STF pôs fim à discussão das atribuições correcionais e características do CNJ, bem como decisão proferida pelo Supremo Tribunal Federal em meados de $2013^{51}$, a qual, em caráter liminar, colocava em xeque o Programa Justiça ao Jovem, que foi criado e organizado pelo CNJ para a execução de medidas socioeducativas de internação, no intuito de aproximar o Judiciário no acompanhamento dessas medidas, entendendo o Min. Dias Toffoli que competiria ao Poder Executivo promover as transferências e as remoções dos adolescentes infratores e não ao Poder Judiciário, em sentido contrário ao entendimento do $\mathrm{CNJ}^{52}$.

No Brasil, o tema é discutido desde os primeiros anos de debate da EC $n^{\circ} 45 / 2004$, ainda no legislativo, mas observa-se que o controle judicial do STF vai mais além de uma função de revisor da atividade administrativa do $\mathrm{CNJ}$, interferindo diretamente nas decisões do Conselho de acordo com seus interesses, destacandose a função de presidente do órgão concomitantemente à presidência da suprema corte e a responsabilidade de julgar eventuais infrações penais contra os membros do Conselho.

Na leitura de Ernani Carvalho e Natália Leitão, o STF tem atuado de forma decisiva no Brasil, constituindo-se hoje em um participante ativo do cenário político em decorrência do seu controle constitucional e desenho institucional traçado pela Constituição de 1988, ocasionando inclusive a criação tardia do CNJ em relação aos demais conselhos de outros países da América Latina, atribuindo-lhe ainda o ônus de subordinação às decisões da suprema corte ${ }^{53}$. Na visão de Roberto Fragale

\footnotetext{
${ }^{50}$ FRANCO; CUNHA, op. cit., 2013, p. 527.

${ }^{51}$ BRASÍLIA, Supremo Tribunal Federal. Processo: Medida Cautelar em Mandado de Segurança 31902. Relator: Min. Dias Toffoli, 2013.

${ }^{52}$ SPOSATO, Karyna Batista; ANDRADE, Marisa Meneses de. Em busca de justiça ao jovem: a difícil articulação entre os poderes. Revista Direito GV, v. 18, p. 555-570, 2013, p. 563.

${ }^{53}$ CARVALHO, Ernani; LEITÃO, Natália. O poder dos juízes: Supremo Tribunal Federal e o desenho institucional do Conselho Nacional de Justiça. Revista de Sociologia e Política, v. 21, p. 13-27, 2013, p. 19.
} 
Filho, a criação do CNJ e as decisões proferidas após os embates das ADIns $\mathrm{n}^{\mathrm{0}} 3.367$ DF e 4.638-DF representam um falso sentimento de vitória da sociedade, pois o que realmente houve foi apenas uma alteração na "arquitetura institucional", cuja "nova configuração" permitiu uma "ligeira abertura" do Poder à sociedade civil ${ }^{54}$, até mesmo porque em seu voto o Min. Cezar Peluso ressaltou à época que o CNJ não representava um controle externo como defendiam alguns, mas sim um órgão interno do Poder Judiciário, o que entende-se não condizer com a genuína intenção de criação do Conselho. Não obstante esse controle judicial do STF, cumpre registrar que dentre os membros do Conselho, oriundos do Poder Judiciário, fica ainda a critério da suprema corte, além da participação do presidente (membro nato que exerce a presidência simultaneamente), a indicação de mais dois membros, um desembargador e um juiz, ambos vinculados a um dos tribunais de justiça estaduais, o que deixa clara a centralização de poder da suprema corte no órgão que deveria ser multi-representativo. Qual seria então o equilíbrio para uma gestão participativa e ausente de interesses políticos?

Em outras palavras, a despeito da intenção de criar-se uma aproximação do Judiciário com a sociedade civil através do CNJ, identifica-se que o controle judicial do STF e a maior participação de membros do Poder Judiciário na composição do Conselho, além da indicação direta de dois de seus membros, apenas concentrou mais poder em uma corte que é estritamente política, potencializando decisões pautadas nos interesses da suprema corte.

Diante da construção do sistema, identifica-se um largo caminho a ser percorrido na operação e funcionamento do Conselho, sendo necessária transformação que viabilize maior autonomia ao CNJ e participação efetiva da sociedade civil, a qual indubitavelmente foi preterida, não havendo hoje controle social externo como o idealizado por Hélio Bicudo quando da apresentação do projeto.

\section{CONSIDERAÇÕES FINAIS}

Diante das precedentes considerações é fácil perceber que ao longo de uma década muitas foram as contribuições do CNJ na gestão do Poder Judiciário. Ele possibilitou a unificação de políticas judiciais, maior controle disciplinar e a

\footnotetext{
${ }^{54}$ FRAGALE FILHO, Roberto. Conselho Nacional de Justiça: desenho institucional, construção de agenda e processo decisório. Revista de Ciências Sociais, v. 56, p. 975-1007, 2013, p. 976.
} 
implementação de sistema de governança de fundamental importância para mudanças significativas como a implementação do processo eletrônico, a prestação de contas para a sociedade (Justiça em Números), a difusão do sistema Bacenjud criado em 2001 pelo Banco Central, a otimização do sistema Infojud e Renajud, o estabelecimento de metas de produtividade, a criação do programa "pai presente", o combate à violência doméstica, o incentivo à conciliação e mediação, entre outros programas de grande alcance social.

É necessário reconhecer ainda que, a partir da existência do CNJ, mesmo com todos os embates e resistências, o Poder Judiciário passou a agir com mais coordenação e mais unidade, tornando evidente a importância do gerenciamento e da aplicação de técnicas de gestão administrativa, proporcionando nova compreensão de sistema judiciário, pautado pela governança corporativa. Por outro lado, embora o corporativismo tenha perdido força com a posição de competência concorrente para apuração disciplinar, que permite ao CNJ instaurar processos administrativos e investigar juízes paralelamente às corregedorias dos Tribunais, ainda é possível identificar um Poder Judiciário distante da sociedade civil, com pouca transparência e retrógrado, características que ficam evidenciadas na história dessa década de criação do CNJ.

A despeito dessa atuação do Conselho na gestão do Judiciário brasileiro, nota-se que a estrutura atual desenhada na Constituição ainda favorece e potencializa a interferência do STF nas decisões do Conselho, o qual deveria exercer suas atividades com maior participação da sociedade civil e maior autonomia, não podendo ficar sujeito às intervenções, em sua maioria políticas, do STF, órgão este que sabidamente exerce forte articulação política na "divisão dos poderes".

Assim, não obstante o desafio no aprimoramento de suas funções e excelência na prestação jurisdicional, a expectativa é ver um $\mathrm{CNJ}$ arrojado e desvinculado do STF, que possibilite agenda de maior aproximação da sociedade civil ao Poder Judiciário e com maior participação do cidadão na gestão desse mesmo Judiciário, proporcionando assim a construção de um Judiciário democrático e participativo.

\section{REFERÊNCIAS}

BARBOSA, Marco Antonio; OLIVEIRA, Bruno Batista Costa. CNJ: Primavera brasileira ou defensor do estamento burocrático? Revista Crítica do Direito, v. 60, p. 1-24, 2014. 
BOCHENEK, Antonio Cesar; DALAZOANA, Vinícius; RISSETTI, Vinícius Rafael. Good governance e o Conselho Nacional de Justiça. Revista Direito GV, v. 18, p. 535-554, 2013.

BRASIL. Associação de Magistrados Brasileiros. Discurso proferido pelo Ministro Nelson Jobim na cerimônia de posse na presidência do STF. Brasília, 03 jun. 2004. Disponível em: <http://www.amb.com.br/portal/docs/discursos/discurso. pdf $>$. Acesso em: 24 set. 2015.

BRASIL. Diário do Congresso Nacional. Brasília, 01 maio. 1992. Disponível em: $<$ http://imagem.camara.gov.br/Imagem/d/pdf/DCD01MAI1992.pdf\# page $=7>$. Acesso em: 24 set. 2015.

BRASÍLIA, Supremo Tribunal Federal. Processo: Medida Cautelar em Mandado de Segurança 31902. Relator: Min. Dias Toffoli, 2013

CAETANO, Flávio Crocce. Dez anos da reforma do judiciário. São Paulo, 16 dez. 2014. Disponível em: <http://politica.estadao.com.br/blogs/fausto-macedo/dezanos-da-reforma-do-judiciario/> . Acesso em: 25 set. 2015.

CARVALHO, Ernani; LEITÃO, Natália. O poder dos juízes: Supremo Tribunal Federal e o desenho institucional do Conselho Nacional de Justiça. Revista de Sociologia e Política, v. 21, p. 13-27, 2013.

CHIMENTI, Ricardo Cunha. A corregedoria nacional de justiça-avanços e resistências. In: STOCO, Rui; PENALVA, Janaína (Org.). Dez anos de reforma do judiciário e o nascimento do Conselho Nacional de Justiça. São Paulo: RT, 2015. p. 361-371.

ESCRIVÃO FILHO, Antônio. Transparência e participação social na indicação de conselheiros para o CNJ. Curitiba, 18 jan. 2012. Disponível em: <http:// terradedireitos.org.br/2012/01/19/transparencia-e-participacao-social-na-indicacaode-conselheiros-para-o-cnj/> . Acesso em: 11 out. 2015

FALCÃO, Joaquim. A história da reforma do poder judiciário e de sua estratégia pré-legislativa. In: STOCO, Rui; PENALVA, Janaína (Org.). Dez anos de reforma do judiciário e o nascimento do Conselho Nacional de Justiça. São Paulo: RT, 2015. p. $177-194$. 
FARIELLO, Luiza de Carvalho. Programa pai presente completa cinco anos e se consolida no país. Brasília, 07 ago. 2015. Disponível em: < http://www.cnj.jus.br/ noticias/cnj/80089-programa-pai-presente-completa-cinco-anos-e-se-consolida-nopais $>$. Acesso em: 12 out. 2015.

FRAGALE FILHO, Roberto. Conselho Nacional de Justiça: desenho institucional, construção de agenda e processo decisório. Revista de Ciências Sociais, v. 56, p. 975-1007, 2013.

FRANCO, Ivan Candido da Silva de; CUNHA, Luciana Gross. O CNJ e os discursos do direito e desenvolvimento. Revista Direito GV, v. 18, p. 515-534, 2013.

FREITAS, Vladimir Passos de. A criação e o papel do Conselho Nacional de Justiça. In: STOCO, Rui; PENALVA, Janaína (Org.). Dez anos de reforma do judiciário e o nascimento do Conselho Nacional de Justiça. São Paulo: RT, 2015. p. 505-513.

GOÉS, Bruno. Fiscalização do Poder Judiciário está entranhada na sociedade brasileira. Rio de Janeiro, 07 out. 2011. Disponível em: < http://oglobo.globo.com/ politica/fiscalizacao-do-poder-judiciario-esta-entranhada-na-sociedade-brasileira-dizhelio-bicudo-2743001> . Acesso em: 27 set. 2015.

GOMIDE, Raphael. Projeto de lei prevê até 17 salários e aumenta benefícios a juízes. Rio de Janeiro, 03 jul. 2015. Disponível em: < http://epoca.globo.com/ tempo/noticia/2015/07/projeto-de-lei-preve-ate-17-salarios-e-aumenta-beneficiosjuizes.html > . Acesso em: 03 out. 2015.

KADANUS, Kelli. Proposta de nova LOMAN aumenta benefícios dos magistrados. Curitiba, 05 jun. 2015. Disponível em: <http://www.gazetadopovo.com.br/ vida-publica/justica-e-direito/proposta-de-nova-loman-aumenta-beneficios-dosmagistrados-7davvag4n9gqi4688re0vboey>. Acesso em: 12 out. 2015.

KOERNER, Andrei; FRAGALE FILHO, Roberto. Do controle externo à participação cidadã: por uma revisão do modelo do judiciário brasileiro. In: STOCO, Rui; PENALVA, Janaína (Org.). Dez anos de reforma do judiciário e o nascimento do Conselho Nacional de Justiça. São Paulo: RT, 2015. p. 61-78. 
em meio às críticas de advogados e servidores. São Paulo, 17 dez. 2013. Disponível em: $\quad<$ http://politica.estadao.com.br/blogs/fausto-macedo/cnj-aprova-processojudicial-eletronico-em-meio-as-criticas-de-advogados-e-servidores/> . Acesso em: 12 out. 2015.

MENDES, Gilmar. Mutirões carcerários, uma aula de Brasil. São Paulo, 16 abr. 2010. Disponível em: <http://opiniao.estadao.com.br/noticias/geral,mutiroescarcerarios-uma-aula-de-brasil,539075> . Acesso em: 12 out. 2015.

MONTENEGRO, Manuel Carlos. Meta de produtividade resultou em 87 milhões de ações julgadas desde 2010. Brasília, 23 jun. 2015. Disponível em: < http:// www.cnj.jus.br/noticias/cnj/79701-meta-de-produtividade-resultou-em-87-milhoesde-acoes-julgadas-desde-2010> . Acesso em: 12 out. 2015.

OTTONI NETTO, Homero Benedicto. Judiciário continua na idade média na era da informação. São Paulo, 22 jul. 2003. Disponível em: < http://www.conjur.com. br/2003-jul-22/judiciario_continua_idade_media_informacao $>$. Acesso em: 24 set. 2015.

PINHEIRO, Aline. Leia a resolução contra o nepotismo aprovada pelo CNJ. São Paulo, 18 out. 2005. Disponível em: < http://www.conjur.com.br/2005-out-18/leia resolucao_nepotismo_aprovada_cnj $>$. Acesso em: 12 out. 2015.

RAMOS, Gisela Gondin. O enterro precoce do CNJ. São Paulo, 09 abr. 2015. Disponível em: <http://politica.estadao.com.br/blogs/fausto-macedo/o-enterroprecoce-do-cnj/> . Acesso em: 25 set. 2015.

REFORMA do judiciário (EC45/04) - 10 anos depois. Migalhas. Brasil. Datado de 17 dez. 2014. Disponível em: < http://www.migalhas.com.br/Quentes/17,MI212874,61044Reforma+do+Judiciario $+\mathrm{EC}+4504+10+$ anos + depois $>$. Acesso em: 25 set. 2015.

RELATÓRIO Índice de Confiança na Justiça Brasileira (ICJ Brasil). Fundação Getúlio Vargas. Disponível em: <https://bibliotecadigital.fgv.br/dspace/ handle/10438/6618 > . Acesso em: 24 out. 2015.

RIBEIRO, Antônio de Pádua. A importância do CNJ na implantação de uma nova ordem judiciária no Brasil. In: STOCO, Rui; PENALVA, Janaína (Org.). Dez anos de 
reforma do judiciário e o nascimento do Conselho Nacional de Justiça. São Paulo: RT, 2015. p. 69-78.

ROCHA, Graciliano. Projeto do STF pode tornar Judiciário maior e mais caro. São Paulo, 24 maio. 2015. Disponível em: <http://www1.folha.uol.com.br/ poder/2015/05/1632909-projeto-do-stf-pode-tornar-judiciario-maior-e-mais-caro. shtml > . Acesso em: 12 out. 2015.

ROLIM, Luciano. Captura corporativista do CNJ. São Paulo, 23 abr. 2015. Disponível em: $\quad<$ http://opiniao.estadao.com.br/noticias/geral,captura-corporativista-do-cnjimp-,1674415>. Acesso em: 10 out. 2015.

SADEK, Maria Tereza (Org.). Reforma do judiciário. São Paulo: Fundação Konrad Adenauer, 2001.

SADEK, Maria Tereza. CNJ: impactos no judiciário e na sociedade. In: STOCO, Rui; PENALVA, Janaína (Org.). Dez anos de reforma do judiciário e o nascimento do Conselho Nacional de Justiça. São Paulo: RT, 2015. p. 293-311.

SCHMIDT, Paulo Luiz. Dez anos de CNJ: constante aprimoramento. In: STOCO, Rui; PENALVA, Janaína (Org.). Dez anos de reforma do judiciário e o nascimento do Conselho Nacional de Justiça. São Paulo: RT, 2015. p. 353-359.

SILVA, Rosane Leal da; HOCH, Patrícia Adriani; RIGHI, Lucas Martins. Transparência pública e a atuação normativa do CNJ. Revista Direito GV, v, 18, p. 489-514, 2013.

SILVA, Técio Lins e. O Conselho Nacional de Justiça na visão de um advogado que viveu os dois lados da tribuna. In: STOCO, Rui; PENALVA, Janaína (Org.). Dez anos de reforma do judiciário e o nascimento do Conselho Nacional de Justiça. São Paulo: RT, 2015. p. 493-503.

SPOSATO, Karyna Batista; ANDRADE, Marisa Meneses de. Em busca de justiça ao jovem: a difícil articulação entre os poderes. Revista Direito GV, v. 18, p. 555-570, 2013.

STOCO, Rui; PENALVA, Janaína (Org.). Dez anos de reforma do judiciário e o nascimento do Conselho Nacional de Justiça. São Paulo: RT, 2015. 
TEIXEIRA, Paulo Eduardo Pinheiro. Mudanças previstas na nova Loman enfraquecem papel no CNJ. São Paulo, 11 abr. 2015. Disponível em: < http://www. conjur.com.br/2015-abr-11/paulo-teixeira-mudancas-previstas-loman-enfraquecemcnj>. Acesso em: 25 set. 2015.

TOMIO, Fabrício Ricardo de Limas; ROBL FILHO, Ilton Norberto. Accountability e independência judiciais: uma análise da competência do Conselho Nacional de Justiça (CNJ). Revista de Sociologia e Política, v. 45, p. 29-46, 2013.

VASCONCELLOS, Marcos de. CNJ puniu cinco magistrados e afastou outros cinco em 2014. São Paulo, 02 fev. 2015. Disponível em: < http://www.conjur.com. br/2015-fev-02/cnj-puniu-cinco-magistrados-afastou-outros-cinco-2014>. Acesso em: 12 out. 2015.

VASCONCELLOS, Marcos de. Conselho Nacional de Justiça aposentou 12 juízes em 2013. São Paulo, 07 jan. 2014. Disponível em: < http://www.conjur.com.br/2014jan-07/doze-magistrados-foram-aposentados-compulsoriamente-cnj-2013>. Acesso em: 12 out. 2015.

VASCONCELOS, Frederico. Projeto põe em risco poder do CNJ, órgão que vigia Judiciário. São Paulo, 04 abr. 2015. Disponível em: <http://www1.folha.uol.com. br/poder/2015/04/1612249-projeto-poe-em-risco-poder-do-cnj-orgao-que-vigiajudiciario.shtml > . Acesso em: 25 set. 2015.

Recebido em: 06 de dezembro de 2015 Aceito em: 01 de março de 2016 